\title{
Sistem Informasi Manajemen Aset dan Inventaris menggunakan $Q R$ Code di Kantor Camat Petang
}

\author{
I Kadek Subudi Setiawan 1), I Nyoman Yudi Anggara Wijaya ${ }^{2)}$ \\ 1)2) Sistem Informasi, STMIK Primakara \\ Jl. Tukad Badung No. 135, Renon, Kec. Denpasar Sel., Kota Denpasar \\ 1) subudisetiawan10@yahoo.com
}

\begin{abstract}
Information and communication technology in this era it's very rapid development. The impact of this information technology is very large felt in supporting the performance and activities ranging from schools, bussinesses and government agencies. Government agencies have used a lot of information systems that help the performance of these agencies to support the speed of the government process, but this information system has not been used as a whole in the government process especially in the sub-district office that still uses manual methods in recording inventory data owned by the agency. This research was made with the waterfall method that begins with the planning process of the system in which in this process a system of planning will be made related to the problems that exist in the camat petang office, then the modeling process where the system in the form of system design will be made, then the process is carried out implementation and testing of systems that have been made. Based on the problems and data obtained, an asset management information system and inventory were made using QR-Code, this system is useful for recording assets, providing information related to assets in a complete and fast way and providing convenience in bleaching items that are damaged or cannot be used anymore.
\end{abstract}

Keywords: simanis, information systems, management, assets, inventory, QR-Code

Intisari-Teknologi informasi dan komunikasi di era sekarang ini perkembanganya sangatlah pesat. Dampak teknologi informasi ini sangat besar dirasakan dalam mendukung kinerja dan berjalanya proses-proses pekerjaan, mulai dari proses kinerja di sekolah, bisnis, dan lembaga pemerintah. Instansi pemerintah telah menggunakan banyak sistem informasi yang membantu kinerja lembaga untuk mendukung kecepatan proses pemerintahanya, namun sistem informasi ini belum digunakan secara keseluruhan dalam proses pemerintahan terutamanya di Kantor Camat Petang yang masih menggunakan metode manual dalam pencatatan data barang inventaris yang dimiliki oleh instansi tersebut. Penelitian ini dibuat dengan metode waterfall yang diawali dengan proses perencanaan sistem dimana dalam proses ini akan dibuat sistem informasi yang berkaitan dengan masalah yang ada pada Kantor Camat Petang, kemudian proses pemodelan dimana sistem dalam bentuk perancangan sistem akan dibuat dalam bentuk desain dari sistem, kemudian proses implementasi sistem dan pengujian sistem terhadap sistem yang sudah di bangun. Berdasarkan masalah dan data yang diperoleh, penulis membuat sebuah Sistem Informasi Manajemen aset dan inventaris menggunakan QR code, sistem ini berguna untuk mencatat aset, memberikan informasi terkait dengan aset secara lengkap, sistem yang cepat dan memberikan kemudahan dalam pemutihan barang yang rusak atau tidak bisa digunakan lagi.

Kata kunci: simanis, sistem informasi, manajemen, aset, inventaris, $Q R$ code

\section{Pendahuluan}

Teknologi informasi di bidang kepemerintahan sangat penting dan tidak dapat dipisahkan dengan proses manajemen, hal ini dikarenakan hampir setiap keputusan manajemen selalu membutuhkan dukungan teknologi informasi termasuk dalam manajemen aset dan inventaris. Setiap organisasi perusahaan swasta maupun pemerintah tentunya memiliki aset dan inventaris baik yang berwujud (tangible) maupun tidak berwujud (intagible). Besarnya investasi yang dimiliki di dalam aset dan inventaris tersebut mengakibatkan perlunya pengelolaan terhadap aset dan inventaris tersebut. Setiap aset dan inventaris yang dimiliki organisasi haruslah di kelola dengan efektif dan efisien sehingga aset dan inventaris tersebut dapat memberikan manfaat tertinggi bagi organisasi tersebut. Pengelolaan aset sudah diatur oleh Peraturan Pemerintah Nomor 27 tahun 2014 tentang Pengelolaan Barang Milik Negara/Daerah [1], dan kemudian ditindaklanjuti dengan Peraturan Menteri 
Dalam Negeri Nomor 16 tahun 2016 tentang Pedoman pengelolaan BMD [2].

Aset dan inventaris yang ada pada Kantor Camat Petang sewaktu waktu mengalami perubahan (penambahan dan pengurangan). Sejauh ini, aset dan inventaris tersebut masih dikelola secara manual dengan cara di tulis dalam buku dan diketik dalam perangkat lunak MS.Excel dalam bentuk daftar inventaris aset. Pencatatan aset dan inventaris yang mengunakan buku dan MS.Excel memiliki keterbatasan yaitu: (1) kurangnya record menyangkut informasi detail aset dan inventaris seperti spesifikasi, tanggal pengadaan, harga pembelian, asal muasal dana, kondisi , nilai susut dan nilai arus aset dan inventaris. (2) sulitnya untuk melakukan opersai perhitungan yang kompleks terhadap aset dan inventaris. (3) boros waktu dan tenaga untuk pengelolaan aset dan inventaris. (4) unit lain tidak dapat mengakses informasi karena data MS.Excel tidak didistribusikan dan hanya dimiliki oleh unit sarana pasarana, dan juga mengakibatkan antar data yang terkait tidak saling terintegrasi atau terhubung sehingga mengakibatkan sering terjadinya kerangkapan data akibat proses input yang berulang-ulang dan data yang tidak konsisten akibat kesalahan dalam proses input data dan, perekapan data yang dilakukan yaitu secara manual sehingga dibutuhkan banyak waktu dalam prosesnya.

Pemersalahan-pemersalahan yang menyangkut pengelolaan aset dan inventaris sebagaimana dijelaskan di atas tidak akan terjadi apabila didukung oleh suatu sistem pengelolaan aset dan inventaris yang terintegrasi dan terstruktur. Karena itulah, penulis memberikan sebuah solusi untuk mengatasi persoalan-persoalan tersebut berupa Sistem Informasi Manajemen Aset dan Inventaris menggunakan QR Code Berbasis WEB di Kantor Camat Petang. Sistem ini akan membantu melakukan penataan aset dan inventaris yang di miliki secara benar, tepat dan efisien, baik dari segi waktu, tenaga (human resource), dan biaya (cost) dimana sistem yang akan dirancang mempunyai fasilitas untuk mengelompokan aset dan inventaris, memasukan jumlah aset dan inventaris, keterangan kondisi masing-masing aset dan inventaris dan hal-hal yang bisa dilakukan lebih spesifik lagi terhadap aset dan inventaris yang ada di kantor camat Petang.

\section{LANDASAN TEORI DAN TINJAUAN PUSTAKA}

\section{A. Landasan Teori}

\section{1) Pengertian Sistem Informasi}

Sistem adalah suatu kumpulan atau himpunan dari unsur, komponen, atau variabel yang terorganisir, saling berinteraksi, saling bergantung satu sama lain, terpadu dan berperan penting dalam komponen pembentuk organisasi yang bersifat tampak secara fisik dan abstrak atau konseptual seperti misi, pekerjaan, kegiatan, klompok dan lain sebagainya [3].

\section{2) Management Aset}

Manajemen adalah ilmu dan seni dalam proses pengaturan, pengorganisasian, perancanaan, perawatan dan pengawasan terhadap pembelian, penggunaan, perawatan, perbaikan, dan penghapusan aset fisik untuk mengoptimalkan potensi pelayanan dan meminimalkan cost sehingga pemanfaatan sumber daya manusia dan sumbersumber lainya dapat dilaksanakan secara efektif dan efisien untuk mencapai suatu tujuan [4].

Aset adalah barang, yang terdiri dari benda tidak bergerak dan bergerak, baik yang berwujud (tangible) yaitu kekayaan yang mempunyai fisik dan (intangible) yaitu kekayaan yang tidak mempunyai fisik namun dapat dikatakan sebagai kekayaan secara terpisah yang tercakup dalam aktiva/kekayaan atau harta kekayaan dari suatu instansi, organisasi, badan usaha ataupun individu perorangan [5]. Manajemen Aset adalah proses pengambilan keputusan dan penerapannya sesuai dengan perolehan, penggunaan dan distribusi aset.

\section{3) Sistem Informasi Manajemen Inventaris dan Aset}

Menurut Hartono [6], "Sistem Informasi Manajemen Aset digunakan untuk pengelolaan aset/ inventori. Implementasi sistem informasi manajemen aset pada hakekatnya adalah upaya untuk tertib dokumen dan administrasi pengelolaan pada aset yang dimiliki. Tertib dokumen aset lebih ke terkaitan dengan pendataan data dan dokumen dengan barang yang tersedia disertai dengan keberadaan aset, sedangkan tertib administrasi lebih dimaksudkan pada upaya membangun prosedur pengelolaan aset mulai saat pengadaan, perubahan data, hingga penghapusan aset".

\section{4) $Q R$ Code}

Quick Response $(Q R)$ code atau kode respon cepat adalah sebuah kode matriks dalam bentuk dua dimensi yang dikembangkan oleh perusahaan Jepang Denso-Wave pada tahun 1994 yang memiliki kemampuan untuk menyimpan data di dalamnya [7].

\section{B. Tinjauan Pustaka}

Tinjauan pustaka menguraikan hasil-hasil penelitian yang pernah dilakukan oleh peneliti sebelumnya yang mempunyai kaitan dengan penelitian ini. Berikut tinjauan pustaka yang terkait dengan penelitian:

1) Analisis dan Perancangan Sistem Informasi Manajemen Aset Berbasis Website pada Biro Pengelolaan Barang Milik Daerah Setda Provinsi Jambi

Penelitian ini menghasilkan prototype sistem informasi manajemen aset yang diharapkan dapat meningkatan dalam pengelolaan aset yang ada pada Biro Pengelolaan Barang Milik Daerah Setda Provinsi Jambi [8].

2) Penerapan Sistem Informasi Berbasis Komputer Untuk Pengelolaan Aset Bagi SMP Muhammadiyah 1 Kartasura

Penelitian sistem informasi pengelolaan aset ini memungkinkan sekolah melakukan pencatatan aset, penelusuran aset dan pelaporan aset secara cepat dan efektif [9].

Dari penelitian-penelitian sebelumnya, penelitian ini terdapat perbedaan dan keterbaruan sistem yang dimiliki seperti: 
1. Pada penelitian yang di buat oleh penulis menggunakan fitur tambah $Q R$ code dalam proses penyimpanan dan pengambilan data aset yang ada, sehingga dalam pengambilan informasi terkait aset yang ada lebih cepat dan Real time dari sistem yang sebelumnya yang tidak menggunakan fitur $Q R$ code.

2. Dalam pengembangan sistem yang akan dibuat oleh penulis menggunakan framework Laravel. Framework Laravel memberikan semua fungsionalitas yang di butuhkan oleh penulis untuk membuat serta mengembangkan sistem seperti otentikasi user, manajemen sesi, dan caching.

\section{Metodologi Penelitian}

Tahap ini penulis melakukan Rancang Bangun Sistem Informasi Manajemen Aset dan Inventaris menggunakan $Q R$ code di Kantor Camat Petang dengan menggunakan metodologi waterfall. Metodologi Waterfall merupakan suatu sistem pendekatan pada pengembangan perangkat lunak yang sistematis, yang terdiri dari beberapa tahap sebagai berikut [10]:

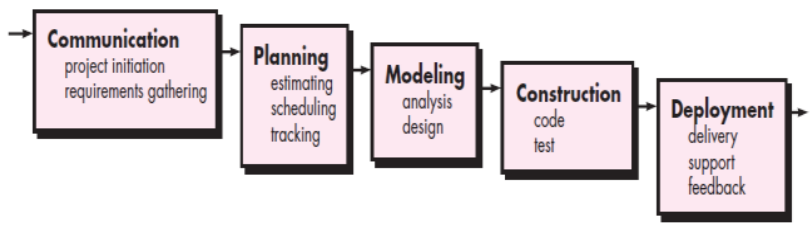

Gambar 3.1 Metode Waterfall

\section{1) Communication (Project Initiation \& Requirements Gathering)}

Melakukan Komunikasi untuk menganalisis permasalahan yang dihadapi dan mengumpulkan data-data yang diperlukan, serta membantu mendefinisikan fitur dan fungsi software. Pengumpulan data-data tambahan bisa juga diambil dari jurnal, artikel, dan internet.

\section{2) Planning (Estimating, Scheduling, Tracking)}

Tahap perencanaan yang menjelaskan tentang estimasi tugas-tugas teknis yang akan dilakukan, resiko-resiko yang dapat terjadi, sumber daya yang diperlukan dalam membuat sistem, produk kerja yang ingin di hasilkan, penjadwalan kerja yang akan di laksanakan, dan tracking proses pengerjaan system.

\section{3) Modeling (Analysis \& Design)}

Tahap perancangan dan permodelan arsitektur sistem yang berfokus pada perancangan struktur data, arsitektur software, tampilan interface, dan algoritma program. Tujuannya untuk lebih memahami gambaran besar dari apa yang akan di kerjakan.

\section{4) Construction (Code \& Test)}

Proses penerjemahan bentuk desain menjadi kode atau bentuk/bahasa yang dapat dibaca oleh mesin. Setelah pengkodean selesai, dilakukan pengujian terhadap sistem dan juga kode yang sudah dibuat. Tujuannya untuk menemukan kesalahan yang mungkin terjadi untuk nantinya diperbaiki.

\section{5) Deployment (Delivery, Support, Feedback)}

Tahapan Deployment merupakan tahapan implementasi software ke customer, pemeliharaan software secara berkala, perbaikan software, evaluasi software, dan pengembangan software berdasarkan umpan balik yang diberikan agar sistem dapat tetap berjalan dan berkembang sesuai dengan fungsinya.

\section{HASIL PEMBAHASAN}

\section{A. Rancangan Penelitian}

Perancangan penelitian tugas akhir ini menggunakan jenis penelitian berbasis deskriptif (descriptive research) yang diartikan sebagai prosedur pemecahan masalah yang diselidiki dengan menggambarkan keadaan subjek atau objek dalam penelitian dapat berupa orang, lembaga, masyarakat penelitian dengan cara yang lebih akurat. Perancangan atau desain sistem terdiri dari beberapa bagian, yaitu: Data Flow Diagram (DFD), Flowchart, Entity Relationship Diagram (ERD), dan Desain User Interface.

1) Data Flow Diagram (DFD)

Pada tahap ini akan dilakukan perancangan DFD sebagai berikut:

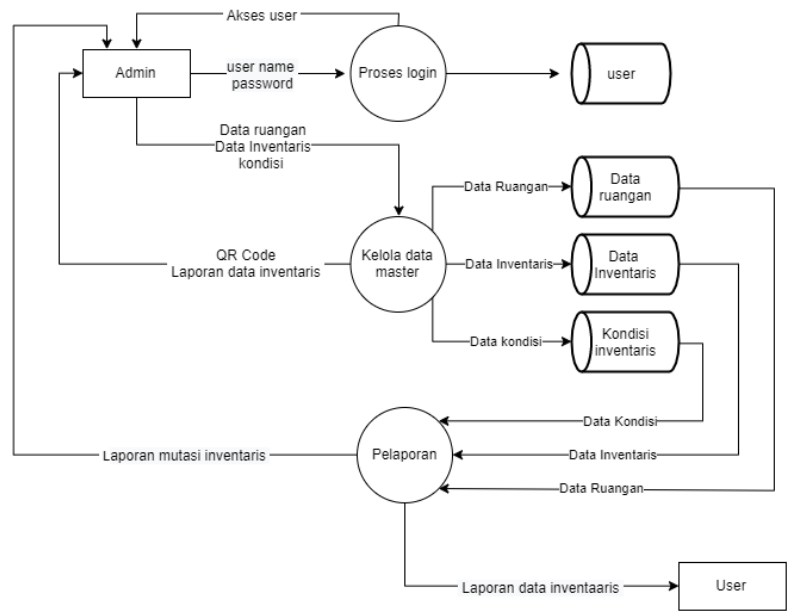

Gambar 1.1 Diagram Level 0

\section{2) Entity Relationship Diagram (ERD)}

Adapun desain Entity Relationship Diagram (ERD) dari sistem Sistem Informasi Manajemen Aset dan Inventaris menggunakan $Q R$ code di kanor camat petang Sebagai berikut: 


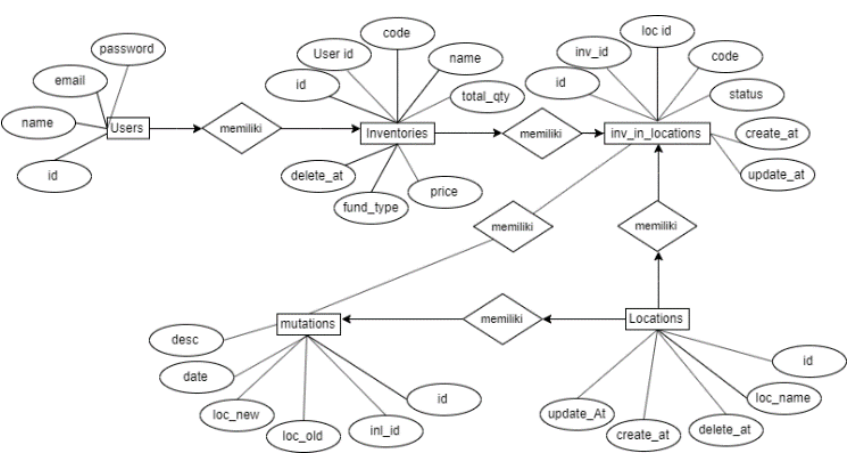

Gambar 4.2 ERD Sistem Informasi Manajemen Aset dan Inventaris

\section{B. Implementasi Sistem}

\section{1) Halaman Login}

Pada halaman Login terdapat beberapa komponen yaitu: input untuk memasukkan Username dan password, serta tombol Login. Tampilan halaman Login dapat dilihat pada gambar

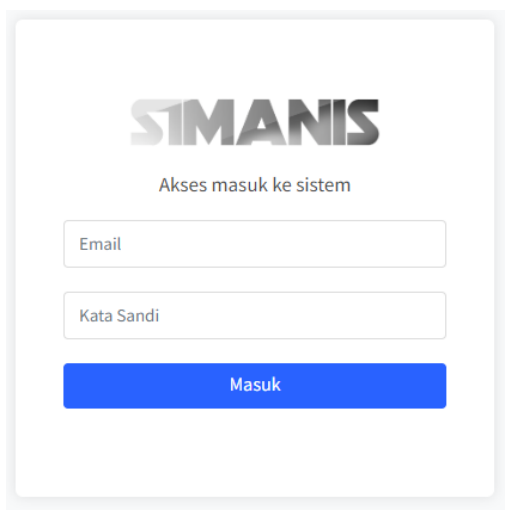

Gambar 4.3 Desain halaman login

\section{2) Halaman Utama admin}

Pada halaman utama Admin terdapat beberapa tampilan data ruangan, total data inventaris, keadaan inventaris, data muatsi dari barang yang sudah di ganti atau di perbaharui dan tombol download untuk mengunduh data mutasi barang yang ada di kantor kecamatan petang. Terlihat pada gambar.

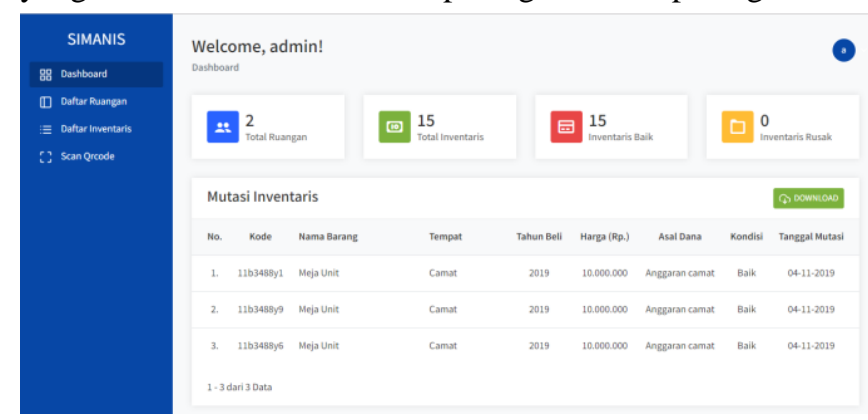

Gambar 4.4 Desain halaman utama admin

\section{3) Halaman Daftar Ruangan}

Pada daftar ruangan terdapat nama ruangan yang terdata, tombol tambah ruangan untuk menambahkan data ruagan baru, icon tambah untuk menambahkan data barang pada ruangan tertentu, icon lihat untuk melihat detail barang yang ada di ruangan, edit untuk mengubah data dan icon hapus untuk menghapus data. Terlihat pada gambar.
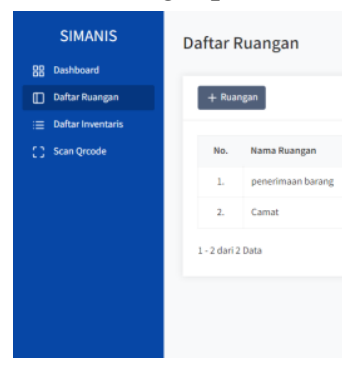

Gambar 4.5 Desain halaman daftar ruangan

\section{4) Halaman Daftar Inventaris}

Halaman daftar inventaris menampilkan data-data barang atau inventaris yang terbagi perkelompok barang dan terbagi kembali dalam sub kelompok barang menjadi per barang dengan kode barang, lokasi dan kondisi barang. Terlihat pada gambar.

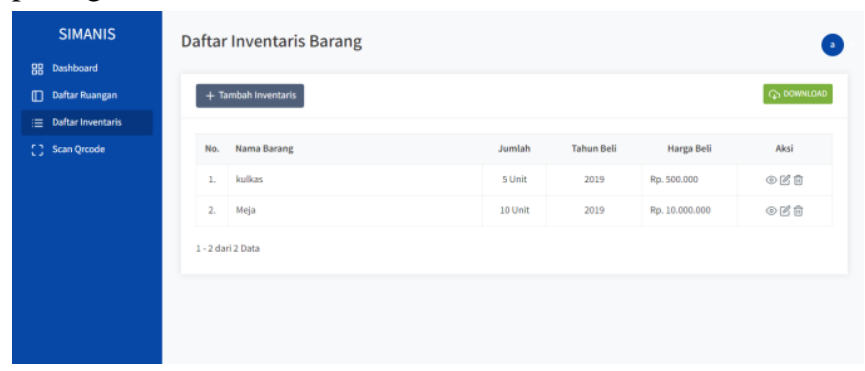

Gambar 4.6 Desain halaman daftar inventaris

5) Halaman Scan $Q R$ code

Pada halaman Scan $Q R$ code ini berisi fitur untuk mengambil gambar dari $Q R$ code dan kemudian sistem akan memberikan data inventaris yang terdata pada $Q R$ code tersebut. Terlihat pada gambar.
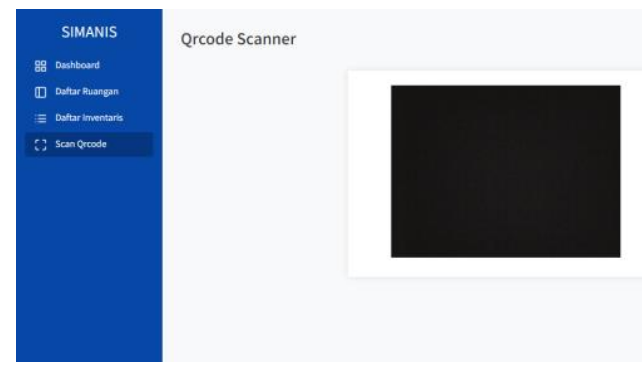

Gambar 4.7 Desain halaman scan QR_Code

\section{6) Halaman Detail Ruangan}

Terlihat pada halaman detail ruangan ini memberikan data ruangan yang terdaftar di sistem serta data barang yang ada di dalamnya termasuk dapat melihat dan mengunduh QR code perbarangnya. Terlihat pada gambar. 


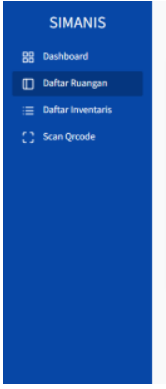

Detail Ruangan

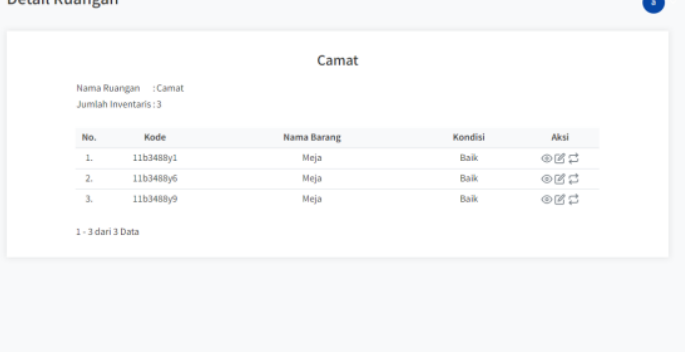

Gambar 4.8 Desain halaman detail ruangan

7) Halaman Detail Inventaris

Pada halaman detail inventaris terdapat data barang atau inventaris yang terdiri dari perbagian inventaris, seperti yang terlampir pada gambar .
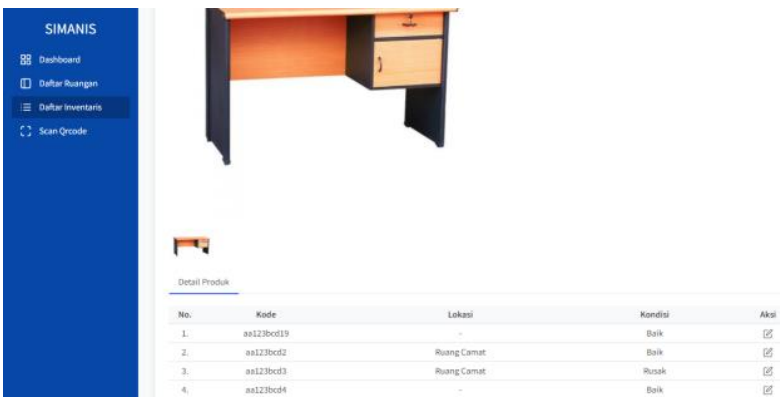

Gambar 4.9 Desain halaman detail inventaris

\section{8) Halaman Tambah Ruangan}

Pada halaman tambahan ruangan ini berfungsi untuk menambahkan data ruangan baru. Terlihat pada gambar.
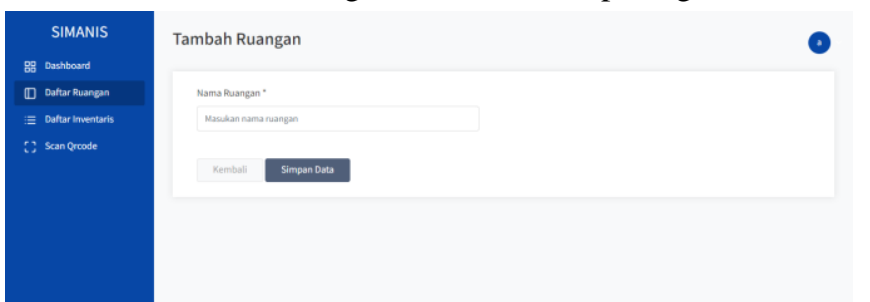

Gambar 4.10 Desain halaman tambah ruangan

9) Halaman Tambah Inventaris

Halaman tambah inventaris ini berfungsi untuk menambahkan barang atau inventaris baru.
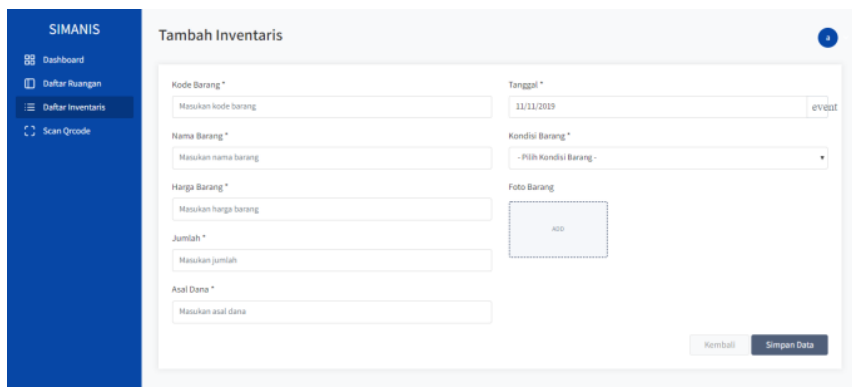

Gambar 4. 11 Desain halaman tmbah inventaris

\section{0) Halaman Pemutihan Barang}

Pada halaman mutasi barang ini berisi perintah untuk memasukan data-data barang serta foto data inventaris yang akan di mutasi atau di putihkan.

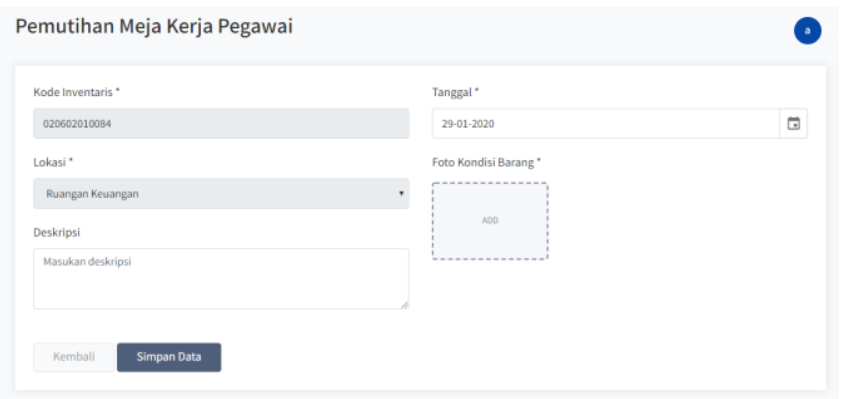

Gambar 4.12 Desain halaman Pemutihan Barang

\section{1) Halaman Laporan Pemutihan Barang}

Halaman laporan pemutihan barang ini memberikan informasi data barang yang sudah dimutasi akibat kondisi yang rusak dan sudah diganti, data ini berfungsi untuk mengetahui jumlah barang yang keluar agar bisa menentukan anggaran untuk barang yang akan dibeli selanjutnya. Terlihat pada gambar.

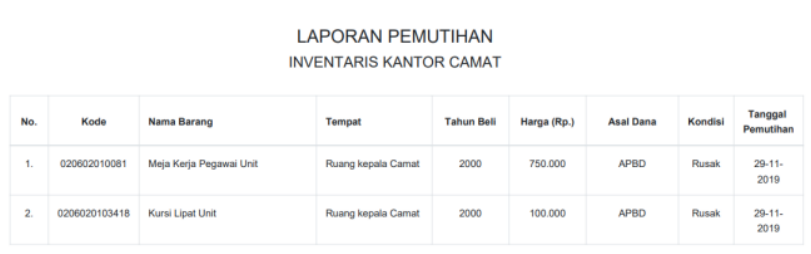

Gambar 4.13 Desain halaman laporan pemutihan barang

\section{2) Halaman Laporan Inventaris}

Pada halaman laporan inventaris memberikan informasi barang atau inventaris secara detail sehingga user dapat mengetahui secara lengkap informasi inventaris yang ada di kantor camat petang. Telihat pada gambar.

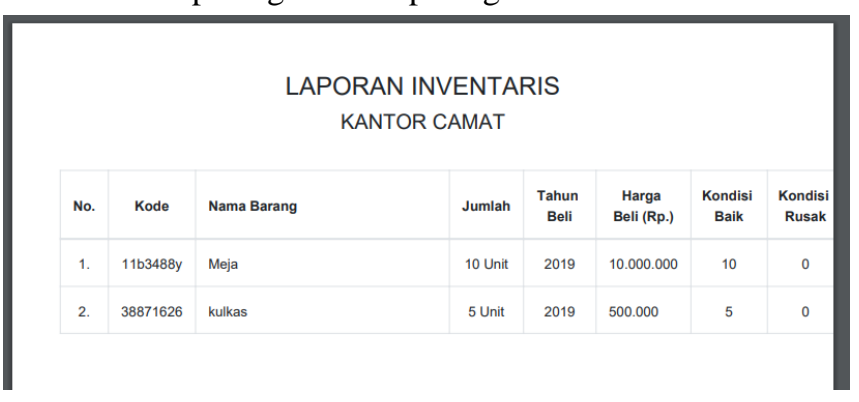

Gambar 4.14 Desain halaman laporan inventaris 


\section{3) Halaman Mutasi Barang}

Pada halaman mutasi inventaris digunakan untuk menambah informasi untuk perpindahan barang atau aset yang ada dari ruangan 1 ke ruangan lainya.
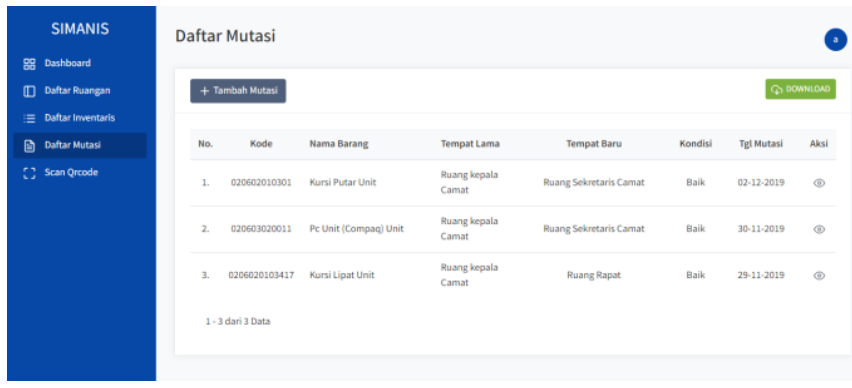

Gambar 4.15 Desain halaman Mutasi Barang

\section{KESIMPULAN DAN SARAN}

\section{A. Kesimpulan}

Berdasarkan hasil pembahasan pengembangan Sistem Informasi Manajemen Aset dan Inventaris menggunakan $Q R$ code di Kantor Camat Petang, adapun kesimpulannya sebagai berikut:

1. Hasil penelitian ini adalah berupa Rancang Bangun Sistem Informasi Manajemen Aset dan Inventaris Menggunakan $Q R$ code di Kantor Camat Petang. Rancang bangun Sistem Informasi Manajemen Aset dan Inventaris menggunakan $Q R$ code di Kantor Camat Petang yang dilakukan pada penelitian ini menggunakan metode waterfall, yaitu mulai tahapan identifikasi permasalahan, pengumpulan data, analisis kebutuhan sistem, desain dan perancangan sistem, pembuatan sistem, pengujian sistem, serta implementasi dan evaluasi sehingga terwujudnya Sistem Informasi Manajemen Aset dan Inventaris menggunakan $Q R$ code Di Kantor Camat Petang .

2. Terdapat beberapa fasilitas atau fitur dalam Sistem Informasi Manajemen Aset dan Inventaris menggunakan $Q R$ code di Kantor Camat Petang, meliputi: pengelolaan data master (user, ruangan kantor, kategori barang, kondisi barang), input ruangan, input inventaris, kondisi barang, $Q R$ code Scanner dan pelaporan inventaris.

B. Saran

Setelah dilakukan penelitian ini, disarankan:

1. Sistem yang telah dibuat dapat dimodifikasi dan dapat dikembangkan lagi untuk mencapai hasil yang jauh lebih baik lagi.
2. Sistem ini bisa dikembangkan lagi di lain instansi dan perusahaan dengan sistem yang sama namun dengan alur yang berbeda

3. Sistem ini belum membahas umur ekonomis dan nilai barang atau aset, disarankan untuk penulis yang menggambil penelitian yang serupa agar menambahkan umur ekonomis dan nilai barang atau aset.

4. Untuk pengembangan berikutnya, penulis menyarankan penulis selanjutnya yang mengambil penelitian yang sama seperi penelitian ini untuk mengembangkanya ke aplikasi mobile. Karena sistem ini akan bekerja lebih maksimal apabila berbentuk aplikasi

\section{REFERENSI}

[1] Peraturan Pemerintah (PP) No. 27 Tahun 2014, Pengelolaan Barang Milik Negara / Daerah. Jakarta.

[2] Permendagri Nomor 19 Tahun 2016, Pedoman Pengelolaan Barang Milik Daerah. Jakarta.

[3] Gaol, chr. Jimmy L. Sistem Informasi Manajemen. Jakarta: Grasindo, 2008

[4] Hasibuan, dan S.P. Malayu, Manajemen Sumber Daya Manusia. Jakarta: Bumi Askara, 2007

[5] Yunita, Irama. Dan Joni Devitra., 2017, Anlisis dan Perancangan Sistem Informasi Manajemen Aset pada SMK Negeri 4 Kota Jambi, Jurnal Manajemen Sistem Informasi Volume 2, No.1, Maret 2017 : 2528-0082.

[6] Hartono. Sistem Informasi Manajemen Aset / Inventory / Logisitk. Jakarta : Andi, 2010.

[7] Nugraha, M Pasca. dan Dr. Ir. Rinaldi Munir M.T., 2011, Pengembangan Aplikasi $Q R$ code Generator dan $Q R$ code Reader dari Data Berbentuk Image 2011: 2087 - 3328.

[8] Fatma, Febrina. Dan Joni Devitra., 2019, Anlisis dan Perancangan Sistem Informasi Manajemen Aset Berbasis Website pada Biro Pengelolaan Barang Milik Setda Propinsi Jambi, Jurnal Manajemen Sistem Informasi Volume 4, No.1, Maret 2019 : 2528-0082.

[9] H. Supriyono, A. M. Noviandri, and Y. E. Purnomo, "Penerapan Sistem Informasi Berbasis Komputer Untuk Pengelolaan Aset Bagi SMP Muhammadiyah 1 Kartasura," in The 6th University Research Colloquium 2017 Universitas Muhammadiyah Magelang, 2017, pp. 59-70.

[10] R. S. Pressman, Rekayasa Perangkat Lunak: Pendekatan Praktisi Buku I. Yogyakarta: Andi, 2015. 